\title{
Norois
}

Environnement, aménagement, société

245 | 2017

Adapter les territoires aux changements climatiques : transition urbanistique et aménagement de l'espace

\section{Elsa RICHARD, L'adaptation aux changements climatiques. Les réponses de l'action publique territorial}

Aude Nuscia Taïbi

\section{(2) OpenEdition \\ Journals}

Édition électronique

URL : http://journals.openedition.org/norois/6257

DOI : $10.4000 /$ norois. 6257

ISBN : 78-2-7535-7465-6

ISSN : $1760-8546$

Éditeur

Presses universitaires de Rennes

Édition imprimée

Date de publication : 31 décembre 2017

Pagination : 127-128

ISBN : 978-2-7535-7456-4

ISSN : 0029-182X

Référence électronique

Aude Nuscia Taïbi, «Elsa RICHARD, L'adaptation aux changements climatiques. Les réponses de l'action publique territorial », Norois [En ligne], 245 | 2017, mis en ligne le 31 décembre 2017, consulté le 05 janvier 2021. URL : http://journals.openedition.org/norois/6257 ; DOI : https://doi.org/10.4000/norois. 6257

(c) Tous droits réservés 


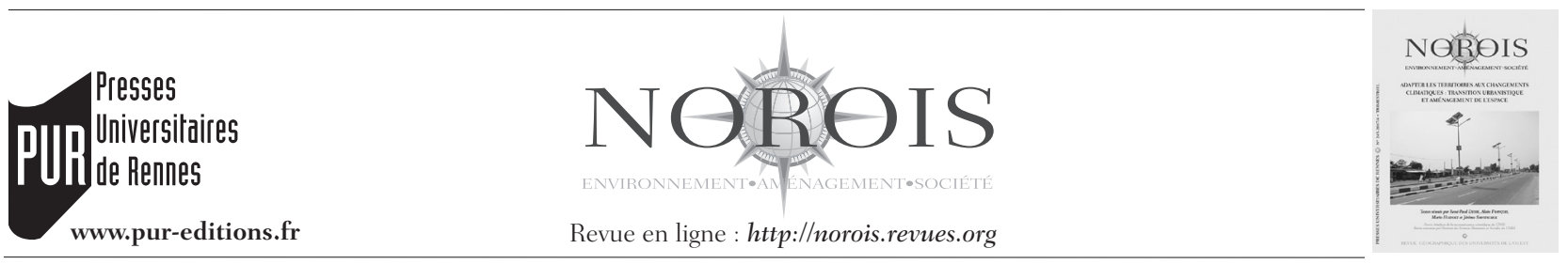

CoMpte RENDU BIBLIOGRAPHiQue

Elsa Richard, 2016. L'adaptation aux changements climatiques. Les réponses de l'action publique territoriale, Rennes, PUR, coll. «Espaces et Territoires », 284 p.

L'adaptation au changement climatique (ACC), objet en vogue actuellement et abondamment utilisé par les chercheurs comme les praticiens de l'aménagement du territoire, n'a pourtant pas de sens stabilisé et partagé, malgré la définition qui en est proposée par le GIEC (IPCC 2001 et 2007).

Cet ouvrage tente de répondre à cette problématique en combinant une analyse théorique et des cas concrets en France.

Après avoir fait un bref rappel de la situation du changement climatique à partir des travaux du GIEC et de l'IPCC, Elsa Richard s'intéresse à la notion même d'adaptation, à l'environnement, à l'anthropocène et donc au changement climatique, en cherchant à comprendre si ces notions et leurs applications font sens en aménagement du territoire. Elle rappelle que ces politiques visant à adapter les sociétés aux impacts du changement climatique sont venues compléter les premières orientées vers l'atténuation du changement climatique avec la réduction des émissions de Gaz à Effet de Serre.

L'auteure interroge ensuite de manière empirique les modalités et difficultés de construction de politiques locales d'ACC à travers quatre contextes géographiques français métropolitains et outre marins.

L'échelle d'analyse est alors celle des territoires locaux soumis à l'injonction législative et politique pour l'intégration des effets du changement climatique dans leurs politiques au sein de l'action

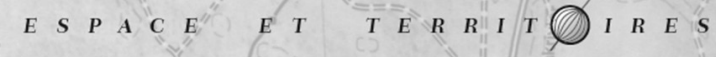

\section{ELSA Richard \\ L'adaptation aux changements climatiques}

Les réponses de l'action publique territoriale

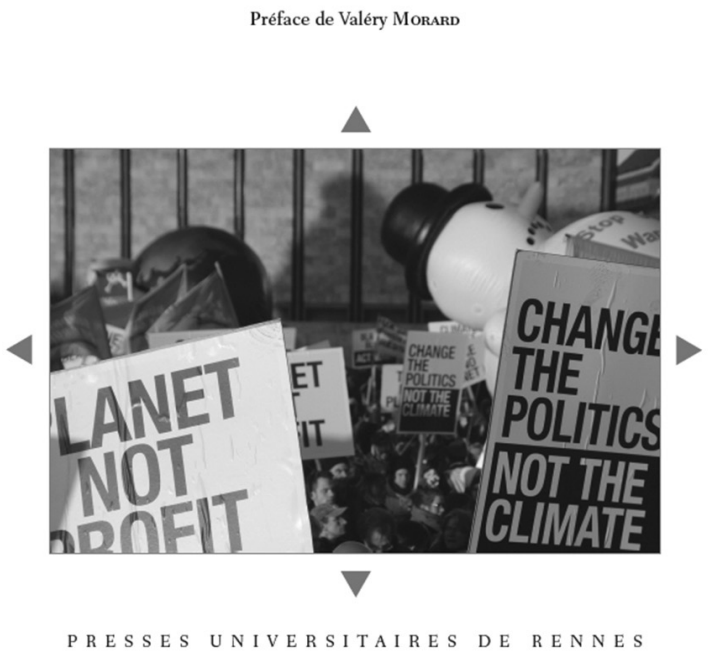

locale. Il s'agit d'une échelle d'observation privilégiée pour appréhender la question de l'inadaptation locale à un problème global. En effet, si des incertitudes perdurent sur l'ampleur des phénomènes et 
la caractérisation fine des conséquences du changement climatique, les observations montrent des impacts notables sur les territoires, sur certaines économies locales et l'environnement ainsi que certaines infrastructures. Par ailleurs, les caractéristiques liées au territoire, tant en termes d'enjeux associés localement (exposition physique, vulnérabilités socio-économiques, ) qu'en termes de capacités d'adaptation (ressources locales, valeurs culturelles, etc.) conduisent à des réponses territoriales d'ACC différenciées.

Au-delà de ces cas concrets, il s'agit pour E. Richard, de montrer que l'intégration de l'ACC dans l'action territoriale modifie les façons de faire et de penser l'aménagement du territoire.

Cet ouvrage à la fois conceptuel et appliqué, est destiné à un public d'étudiants et d'enseignantschercheurs en géographie ainsi qu'aux professionnels de l'aménagement des territoires confrontés à ces nouveaux concepts et contextes flous alors qu'il s'agit d'enjeux majeurs et que les injonctions législatives sont de plus en plus pressantes.

Aude Nuscia TAÏBI université d'Angers 